\title{
The Effects of Thylakoid-Rich Spinach Extract Combined with the Calorie-Restricted Diet on Cardiometabolic Risk Factors in Obese Women with Polycystic Ovary Syndrome: A Randomized Controlled Clinical Trial
}

Fatemeh Pourteymour Fard Tabrizi

Tabriz University of Medical Sciences

Mahdieh Abbasalizad Farhangi ( $\sim$ abbasalizad_m@yahoo.com )

Tabriz University of Medical Sciences

Maryam Vaezi

Tabriz University of Medical Sciences

Salar Hemmati

Tabriz University of Medical Sciences

Research

Keywords: Polycystic ovary syndrome, Obesity, Cardiometabolic, Thylakoid-rich spinach extract, Spinach extract

Posted Date: May 20th, 2020

DOI: https://doi.org/10.21203/rs.3.rs-29599/v1

License: (c) (i) This work is licensed under a Creative Commons Attribution 4.0 International License. Read Full License 


\section{Abstract}

Background: The polycystic ovary syndrome (PCOS) was associated with a higher risk of cardiovascular diseases, related to metabolic dysfunction, due to its peculiar hormonal pattern, dyslipidemia, and inflammatory state. This study was aimed to investigate the effects of thylakoid-rich spinach extract supplementation combined with a hypocaloric diet on cardiometabolic risk factors in obese women with PCOS.

Methods: In a double-blind, placebo-controlled design, forty-eight participants (age 20-45 years) consumed in random order either a thylakoid-rich spinach extract powder $(5 \mathrm{~g})$ or a matched placebo $(5 \mathrm{~g}$ starch), given daily combined with the hypocaloric diet for 12 weeks. The samples were collected at baseline and after the end of the supplementation. The primary outcome was the measure of anthropometric changes, glycemic indices, and lipid profile. The secondary outcomes included inflammatory status and blood pressure.

Results: Thylakoid-rich spinach extract supplementation combined with the restricted-calorie diet was associated with significant reductions in abdominal obesity indicators, insulin resistance, lipid accumulation product (LAP), and diastolic blood pressure (DBP) $(P<0.05)$. Significant decreases were also seen in serum triglycerides (TG), insulin, high-sensitivity C-reactive protein (hs-CRP), and total testosterone compared with the placebo group $(P<0.05)$. However, no significant differences in systolic blood pressure (SBP) and in serum levels of total cholesterol, low-density lipoprotein cholesterol (LDL-C), high-density lipoprotein-cholesterol (HDL-C), and fasting blood glucose were evident between groups at the end of study $(P>0.05)$.

Conclusions: Thylakoid-rich spinach extract supplementation combined with the calorie restriction for 12 weeks may improve the cardiometabolic risk factors in obese women with PCOS.

Trial registration: The study was approved by the Ethics Committee of Research Vice-chancellor of Tabriz University of Medical Sciences, Tabriz, Iran, and was registered in the Iranian Registry of Clinical Trials (IRCT20140907019082N9).

\section{Background}

Polycystic ovary syndrome (PCOS), a heterogeneous infertility disorder, is the most common endocrinopathy in women of reproductive age[1]. Based on the diagnostic criteria and screening population, worldwide prevalence of PCOS ranging from 5 to $20 \%$ of premenopausal women [2]. According to the Rotterdam criteria, $19.5 \%$ of Iranian women suffer from PCOS [3]. Typical clinical features of PCOS, including irregular menstrual cycles, oligomenorrhea, androgenic alopecia, acne, hirsutism, and infertility, affect the majority of women with PCOS and impair their quality of life $[4,5]$. Despite not fully recognized precise pathophysiology of PCOS, evidence supports the central roles of insulin resistance, compensatory hyperinsulinemia, and hyperandrogenism in this syndrome [6]. Hyperandrogenemia influences body fat distribution as an increase in visceral and abdominal obesity 
and contributes to adipose tissue dysfunction leading to insulin resistance [7]. Obesity, in particular of visceral origin, as a common feature of PCOS, significantly influences the severity of both reproductive and cardiometabolic disturbances in these patients. Moreover, the presence of hyperandrogenism and insulin resistance in these subjects worsen their cardiometabolic profile [8,9]. According to published data, atherogenic dyslipidemia (in up to $70 \%$ of PCOS patients), increased oxidative stress, chronic inflammation (mainly, elevated C-reactive protein (CRP)), and subclinical atherosclerosis are more common cardiometabolic risk factors among women with PCOS $[10,11]$. Up to now, there is no definite remedy for the cure of PCOS, and currently, available therapeutics are often used only to control PCOS signs and symptoms. There is growing evidence suggesting the lifestyle modifications, including favorable changes in diet and nutrition and weight loss, should be used in addition to medical treatments for optimal results in the management of underlying metabolic disorders, reduction of risk factors for cardiovascular disease and type 2 diabetes in this group of patients [12]. In this regard, medical literature demonstrated that a weight loss of $5-10 \%$ could restore regular menstruation and improve ovulatory function and pregnancy rates, with reductions of insulin and free testosterone levels [13]. The calorierestricted diet is first-line therapy for weight loss. In order to increase adhering to a low-calorie diet for weight loss, and keeping it, there is often a high tendency to recommend anti-obesity herbal supplements without side effects to consumers [14]. A recently systematic review of published studies reported the anti-obesity and appetite suppressant effects of the thylakoid-rich spinach leaf extract [15]. This extract has anti-inflammatory, anti-proliferative, antioxidative, and anti-obesity effects in biological systems. Spinach, a dark green leafy vegetable, as one of the most nutritious foods, is rich in thylakoids, biological membranes of chloroplast found in green plants. These membranes (thylakoids) are responsible for the light reaction of photosynthesis[15]. Several studies found that the intake of spinach-derived thylakoids was helpful in losing weight, control energy balance, and reduce abdominal fat mass and waist circumference. Further, these membranes have promoted satiety and delayed intestinal digestion of fat in animal models and clinical trials without reports of toxicity or serious side effects [16-18]. This evidence suggests the probable effectiveness of thylakoid-rich spinach extract supplementation for obese women with PCOS. We hypothesized that thylakoid-rich spinach extract intake might affect cardio-metabolic profiles in obese women with PCOS. To our knowledge, no study has yet examined the effects of thylakoid-rich spinach extract intake on the cardio-metabolic status in women with PCOS. Therefore, this

study aimed to investigate the effects of 12 weeks intake of thylakoid-rich spinach extract combined with a low-calorie diet on the cardiometabolic risk factors, including abdominal obesity indicators, glycemic indices, lipid profile, blood pressure, total testosterone, free androgen index (FAl), and hs-CRP in obese women with PCOS.

\section{Methods}

\section{Study design and Participants}

The study was a randomized, double-blind, placebo-controlled clinical trial; that was conducted in Tabriz, Iran, from September 2018 through May 2019. The target population of the present study was obese 
women with PCOS. The PCOS was diagnosed by a gynecologist, based on the Rotterdam criteria, which includes suffering from two of the following symptoms: (i) amenorrhea or oligomenorrhea with eight or fewer menstruations in the previous 12 months, (ii) biochemical and/or clinical signs of hyperandrogenism, and (iii) polycystic ovaries on ultrasound examination ( $>12$ follicles, 2 to $9 \mathrm{~mm}$ in diameter and/or increased ovarian volume $>10 \mathrm{~mL}$ )[19]. The study population was recruited from the gynecology and infertility clinics of Alzahra Hospital in Tabriz, Iran, or Sheykholrayis Polyclinic in Tabriz, Iran. Medical records of patients in these clinical settings were carefully reviewed. Of those, forty-eight obese women (body mass index (BMI): $30-40 \mathrm{~kg} / \mathrm{m}^{2}$ ) with PCOS and aged $20-45$ years, were recruited. Exclusion criteria were as follows: any evidence of thyroid disease, adrenocortical dysfunction, or hyperprolactinemia (Prolactin $>30 \mathrm{mg} / \mathrm{mL}$ ), being menopause, or pregnant, or lactating; smoking or being exposed to cigarette smoke; having co-morbidity with other gynecologic or endocrine disease, or hepatic, renal, or cardiovascular disease, diabetes and/or impaired glucose tolerance; taking any nutritional or herbal supplements during two months prior to the study, using ovulation induction agents or drugs affecting metabolic or insulin statuses such as statins, thiazolidinediones, corticosteroids, insulin, antiobesity and anti-diabetic drugs (including Metformin). Comprehensive interviews on the general characteristics of the participants, containing age, family history of PCOS, disease and medication history or previously utilized treatments, and their lifestyle, were conducted at the beginning of the trial. If the patients had adopted a diet and/or a specific physical activity program, or any changes in medications, or experienced any detrimental events during the study, they were withdrawn from this clinical trial. This clinical trial was registered in the Iranian Registry of Clinical Trials (http://www.irct.ir; registration no. IRCT20140907019082N9).

\section{Ethics approval and consent to participate}

The eligible patients were given a detailed explanation of the study procedures. Written informed consent was obtained from those willing to participate in the trial. The study protocol was conducted according to the Declaration of Helsinki guideline and approved by the ethics committee of Research Vice-Chancellor of Tabriz University of Medical Sciences (Tabriz, Iran; Ethics code: IR.TBZMED.REC.1397.447).

\section{Sample size}

The sample size was calculated based on the previous study [20]. By considering the changes in FBS, with a confidence level of $95 \%$, alpha $=0.05$ and power of $90 \%$, a total of 21 participants were calculated for each group, which was increased to 24 to cover a probable dropout rate of 15\% (total sample size: 48 obese women with PCOS). For this calculation, Power Analysis and Sample Size Software (PASS; NCSS, LLC, US) version 15 was used.

\section{Study protocol}


The study participants were randomly allocated into one of the two experimental groups (in a 1:1 ratio) by a research assistant not otherwise involved in the study, using of the Random allocation software (RAS) and randomized block procedure of size two (age (<33 vs. $\geq 33$ ) and BMI ( $<35 \mathrm{~kg} / \mathrm{m}^{2} \mathrm{vs}$.

$\left.\geq 35 \mathrm{~kg} / \mathrm{m}^{2}\right)$ ). The researchers and participants were blinded regarding the randomization, allocation, and subjects' groups until the end of the study and the completion of final analyses. To ensure the blinding in the evaluation process, the person (completely irrelevant to the study) who prepared the supplement packages assigned a three-digit code to each of the treatments. The eligible subjects were assigned to receive $5 \mathrm{~g}$ /day of thylakoid-rich spinach extract or matching placebo as $5 \mathrm{~g} /$ day raw starch (one sachet before lunch) for 12 weeks. The sachets were completely identical in all other aspects (shape, weight, color). The primary outcomes were changes in anthropometric and metabolic status (FBS, insulin, insulin resistance, and lipid profile). The secondary outcomes were blood pressure, triglyceride glucose (TyG) index, lipid accumulation product (LAP), visceral adiposity index (VAl), and hs-CRP. At first, demographic and clinical questionnaires, a 3-days food record, and international physical activity questionnaire-short form (IPAQ-SF) were completed for all participants. Next, anthropometric assessments and blood pressure measurements were done. All mentioned assessments were performed at baseline and at the end of the study. For biochemical evaluations, blood samples were taken from each patient, after 10$12 \mathrm{~h}$ of overnight fasting, at baseline and end of the study. The participants were asked to keep their regular medication (i.e., OCP) and usual levels of physical activity throughout the study period. They were also advised to inform the researchers for any changes in their medical therapy program and also any adverse effects of the supplements.

\section{Intervention protocol}

Participants randomly recruited to a 12-week intervention arm consisting of $5 \mathrm{~g} /$ day of thylakoid-rich spinach extract powder + low-calorie diet $(n=24)$ or to a control arm of $5 \mathrm{~g} /$ day powdered raw starch as placebo + low-calorie diet $(n=24)$. The choice of 12-weeks intervention duration and a dose of $5 \mathrm{~g} /$ day thylakoid, was based on observed beneficial effects of thylakoid supplementation on obesity status and related metabolic profiles in consumer subjects [21]. All of the participants received a calorie-restricted diet planned by an expert dietitian. For planning this diet, total energy expenditure was calculated based on resting energy expenditure (REE), which was calculated based on the Mifflin equation [22], physical activity level, and thermic effect of food ( $10 \%$ of total energy expenditure). After calculating the daily required energy for each participant, by a $500 \mathrm{kcal}$ deficit from it, individualized diets were designed. The assigned diet contained $30 \%$ fat, $55 \%$ carbohydrate, and $15 \%$ protein. The participants were requested to follow healthy eating recommendations, including changing cooking methods to healthier ways and limiting fast foods, saturated fats, high-fat foods, sugar, sweets, and sugar-sweetened beverages. Food Exchange utilization was thoroughly explained to the participants, and replacing the foods they did not have access to, by the foods of equal calorie from the corresponding food groups was instructed. Adherence to the recommended diet was evaluated using a 3-day food diary ( 2 weekdays and 1 weekend 
day) at baseline and end of the study. Daily intakes of macro- and micro-nutrients were analyzed by Nutritionist IV software (First Databank Inc., Hearst Corp., San Bruno, CA, USA).

\section{Preparation of spinach thylakoids and placebo}

Fresh baby spinach leaves (Spinacia oleracea) were used to prepare of thylakoid membranes according to the previously registered protocols $[16,23,24]$. The required spinach was collected from Tabriz, East Azerbaijan Province, Iran in spring, 2018; some plant samples were delivered to the Herbarium Center of the Faculty of Pharmacy, Tabriz University of Medical Sciences. The scientific name of the collected specimen is Spinacia oleracea L. belonging to the Oleracea family with the herbarium number TBZ-fph1898. The thylakoid supplement used in this investigation was prepared based on the method described by Emerk et al. [24], at an experimental scale in the Synthesis Laboratory of Drug Applied Research Center, Tabriz University of Medical Sciences. Fresh spinach leaves after removing the stems and veins, were washed and drenched. $1000 \mathrm{~g}$ spinach leaves were homogenized with $1250 \mathrm{ml}$ water in a blender and filtered through four layers of Monodur polyester mesh $(20 \mu \mathrm{m})$. This obtained filtrate was diluted 10 times with distilled water, and its $\mathrm{pH}$ adjusted to 4.7 with Hydrochloric acid $(\mathrm{HCl})$. $\mathrm{PH} 4.7$ is the isoelectric point of the thylakoids, and maximum precipitation occurs at this $\mathrm{pH}$. The thylakoids flocculated, and a green precipitate with a clear, a bit yellowish supernatant was obtained after $4 \mathrm{~h}$ standing in the cold $\left(-4^{\circ} \mathrm{C}\right)$. The supernatant was removed, and the green precipitate was collected from the filtrate thylakoids at $\mathrm{pH} 4.7$ and washed in water by repeated centrifugation; the precipitation was repeated at the same $\mathrm{pH}$. The washed thylakoids were collected, and after adjusting to the desired $\mathrm{pH}(\mathrm{pH} 7.0)$, the final sediments freeze-dried to obtain a green thylakoid powder. Large scale production, of this freeze-dried thylakoid powder, was conducted by the Iran Darook Pharmaceutical Co., Tehran, Iran. Placebo consisted of corn starch, which was colored in edible green color, and like thylakoid powder, flavored with kiwifruit essence. Therefore, green powders with kiwifruit flavor were made of thylakoid or placebo, which appearances (shape, size, and color) and also, flavor were similar in placebo and thylakoid. Next, they were packed in completely identical sachets; and each sachet contained $5 \mathrm{~g}$ of thylakoid or $5 \mathrm{~g}$ of starch. The contents of the sachets were dissolved in a glass of water and drunk before lunch. Both participants and researchers were unaware of group assignment. Packages were coded; and distributed monthly by a third person, who was irrelevant to the study. For reminding the consumption of the supplements, a chart was designed for the participants to complete and return in each visit. Participants received a brief daily cell phone reminder and weekly a phone call to take the supplement and to minimize withdrawal and ensure their adherence to the study protocol. The participants were requested to return the remaining sachets at each visit; counting these sachets enabled us to evaluate compliance. Consuming $\geq 80 \%$ of the supplements was considered compliance.

\section{Assessment of anthropometric variables and blood pressure}


The body weight, height, waist, and hip circumferences of the participants were measured at baseline and at the end of the study. Body weight (to the nearest $0.1 \mathrm{~kg}$ ) and height (to the nearest $0.1 \mathrm{~cm}$ ) were measured using a Seca digital scale (Hamburg, Germany), in an overnight fasting state with minimal clothing and no shoes on. BMI was calculated as weight $(\mathrm{kg})$ divided by height squared $\left(\mathrm{m}^{2}\right)$. The hip circumference $(\mathrm{HC})$ was measured at the level of the maximum extension of the buttocks, and waist circumference (WC) was measured at the midpoint between the lower ribs and the iliac crest. Waist to height ratio $(\mathrm{WHtR})$ was calculated as $\mathrm{WC}(\mathrm{cm})$ divided by height $(\mathrm{cm})$. Waist to hip ratio (WHR) was calculated as WC $(\mathrm{cm})$ divided by $\mathrm{HC}(\mathrm{cm})$. Blood pressure was measured in a sitting position three times after resting for $10 \mathrm{~min}$, by a digital sphygmomanometer (Omron M3, Kyoto, Japan), and the mean of three measurements was reported as the final systolic and diastolic blood pressure.

\section{Blood sampling and measurements of biochemical parameters}

The venous blood sample $(10 \mathrm{ml})$ was drawn from each participant at baseline and end of the study after overnight fasting, between 8:00 a.m. and 9:00 a.m. during the early follicular phase (d 2-5) of a spontaneous or P-induced menstrual cycle. Blood samples immediately centrifuged at $3500 \mathrm{rpm}$ for 10 minutes to the separation of serum samples from whole blood. Serum samples were used to measure lipid profile, FBS, insulin, testosterone, sex hormone-binding globulin (SHBG), and hs-CRP. The biochemical parameters, including a lipid profile, glycemic parameters, and hs-CRP were immediately measured after sample collection, and the remaining serum was frozen immediately at $-80^{\circ} \mathrm{C}$, until the end of the study. Serum FBS, triglycerides (TG), total cholesterol (TC), and high-density lipoprotein cholesterol (HDL-C) concentrations were measured through enzymatic methods by an auto-analyzer (Hitachi-917, Tokyo, Japan) using the colorimetric technique, by commercial kits (Pars-Azmoon Co., Tehran, Iran). The Friedewald equation was used to calculate low-density lipoprotein cholesterol (LDL-C) [25]. Serum insulin level was measured by chemiluminescence (IMMULITE 2000, SIEMENS); and the homeostatic model of assessment for insulin resistance (HOMA-IR) was calculated, on the basis of the suggested formula [26]. Serum hs-CRP concentration was determined using an immunoturbidimetric assay (Pars Azmoon Co., Tehran, Iran). Testosterone and SHBG concentrations were determined using ELISA kits (Bioassay Technology Laboratory, Shanghai Korean Biotech, Shanghai City, China) according to the manufacturer's instructions with inter- and intra-assay coefficient variances (CVs) lower than 7\%. The free androgen index (FAl) was calculated based on suggested formulas [27]. TyG index, LAP, and VAl were calculated based on suggested formulas as follows [28]:

TyG $=\operatorname{Ln}[T G(m g / d l) \times F B S(m g / d l) / 2]$,

$\mathrm{LAP}=[\mathrm{WC}(\mathrm{cm})-58] \times[\mathrm{TG}(\mathrm{mmol} / \mathrm{L})]$,

$\mathrm{VAl}=[\mathrm{WC}(\mathrm{cm}) / 36.58+(1.89 \times \mathrm{BMI})] \times(\mathrm{TG}(\mathrm{mmol} / \mathrm{L}) / 0.81) \times(1.52 / \mathrm{HDL}-\mathrm{C}(\mathrm{mmol} / \mathrm{L}))$. 


\section{Statistical analysis}

All statistical analyses were performed using SPSS version 23 (SPSS Inc., Chicago, IL, USA). The Kolmogorov-Smirnov test was performed to determine the normality of data distribution. Distribution of data was expressed as mean (SD) for normally distributed and median (percentiles 25 and 75) for not normally distributed quantitative data and frequency (percent) for qualitative data. To compare the two groups at the baseline, independent sample t-tests or Mann-Whitney or chi-squared tests were used. Assessments of differences within the group were made by paired-samples t-tests or nonparametric Wilcoxon signed-rank test, and sign test. A comparison of the two groups at the end of the study was completed by the analysis of covariance (ANCOVA) after adjusting for the baseline parameters and covariates. Post hoc paired comparisons were made by using a Sidak test. Results with $P$ values of $<0.05$ were considered statistically significant.

\section{Results}

\section{Baseline characteristics of participants}

In this study, from 179 eligible participants, initially, 48 participants were recruited, whom 44 participants completed the trial (intervention group, $n=21$; control group, $n=23$; Fig. 1). The reasons for the loss to follow up are explained in the study flow diagram (Fig. 1). No subject reported any adverse event throughout the study. In this study, adherence and compliance rate were high, which were assessed monthly by counting the number of used sachets. The average consumption was greater than $90 \%$ in both groups. The mean age and weight of the participants were $31.95 \pm 2.59$ years and $88.65 \pm 6.85 \mathrm{~kg}$, respectively, $68.2 \%$ of the participants were married, and half of the subjects $(50 \%)$ had an academic education level. No significant differences were seen between the two groups regarding the initial characteristics at baseline ( $P>0.05$; Table 1$)$. Additionally, as shown in Table 1 , no significant differences were found between the two groups in terms of components of metabolic syndrome. There were no significant differences between the two groups regarding physical activity levels, at baseline, and end of the study $(P>0.05)$. 
Table 1

General characteristics of participants according to the study groups.

\begin{tabular}{|c|c|c|c|}
\hline Variable & Thylakoid group $(n=21)$ & Placebo group(n = 23) & $P$ \\
\hline Age (y) & $31.86(2.35)$ & $32.04(2.83)$ & $0.81^{\mathrm{a}}$ \\
\hline BMI at study baseline $\left(\mathrm{kg} / \mathrm{m}^{2}\right)$ & $35.13(2.16)$ & $35.31(2.77)$ & $0.80^{a}$ \\
\hline BMI at end-of-trial $\left(\mathrm{kg} / \mathrm{m}^{2}\right)$ & $32.38(2.08)$ & $34.03(2.60)$ & $0.03^{a}$ \\
\hline Physical activity (MET-min/week) & $231.0(198.0,396.0)$ & $297.0(231.0,396.0)$ & $0.52^{\mathrm{b}}$ \\
\hline Baseline & $231.0(198.0,396.0)$ & $297.0(231.0,396.0)$ & $0.46^{b}$ \\
\hline End & 0.18 & 0.08 & $0.71^{d}$ \\
\hline$P^{c}$ & $21(100 \%)$ & $23(100 \%)$ & \\
\hline Metabolic syndrome components: ${ }^{1}$ & $21(100 \%)$ & $23(100 \%)$ & 0.49 \\
\hline$W C>88 \mathrm{~cm}$ & $8(38.1 \%)$ & $9(39.1 \%)$ & $0.64^{d}$ \\
\hline $\mathrm{HDL}<50 \mathrm{mg} / \mathrm{dl}$ & $21(100 \%)$ & $23(100 \%)$ & $0.67^{d}$ \\
\hline $\mathrm{SBP} \geq 130 \mathrm{mmHg}$ & $7(33.3 \%)$ & $9(39.1 \%)$ & $0.45^{d}$ \\
\hline $\mathrm{DBP} \geq 85 \mathrm{mmHg}$ & $2(9.5 \%)$ & $7(30.4 \%)$ & $0.74^{d}$ \\
\hline \multicolumn{4}{|l|}{$\mathrm{TG} \geq 150 \mathrm{mg} / \mathrm{dl}$} \\
\hline \multicolumn{4}{|l|}{$\mathrm{FBS} \geq 100 \mathrm{mg} / \mathrm{dl}$} \\
\hline \multicolumn{4}{|c|}{$\begin{array}{l}\text { BMI, body mass index; DBP, diastolic blood pressure; FBS, fasting blood sugar; HDL, high-density } \\
\text { lipoprotein-cholesterol; MET, metabolic equivalent of task; SBP, systolic blood pressure; TG, } \\
\text { triglycerides; WC, waist circumference. }\end{array}$} \\
\hline \multicolumn{4}{|c|}{ 1: Metabolic syndrome definition according to the NCEP-ATP III criteria. } \\
\hline \multicolumn{4}{|c|}{$\begin{array}{l}\text { Age and BMI are presented as mean (SD); physical activity (MET-min/week) variables are presented } \\
\text { as median ( } 25 \text { th and } 75 \text { th percentiles); metabolic syndrome component variables are presented as n } \\
(\%) \text {. }\end{array}$} \\
\hline \multicolumn{4}{|c|}{ a $P$ based on Independent-samples t-test. } \\
\hline \multicolumn{4}{|l|}{ b $P$ based on Mann Whitney U test } \\
\hline \multicolumn{4}{|l|}{ c $P$ based on Wilcoxon test } \\
\hline $\mathrm{d} P$ based on chi square test & & & \\
\hline
\end{tabular}

\section{Dietary intakes}


Dietary intakes of participants were indicated in Table 2. No significant between-group differences were observed in average daily intake of energy, macronutrients, and dietary fiber at baseline $(P>0.05)$, except for SFA and MUFA, which were higher in the thylakoid group than the placebo group $(P<0.05$; Table 2$)$. As expected, after 12 weeks of the intervention, energy intake significantly decreased in both groups compared to baseline, due to receiving a calorie-restricted diet by both groups. The dietary intake of carbohydrate, total fat, SFA, PUFA, and MUFA significantly decreased during the intervention period in both thylakoid and placebo groups $(P<0.05)$. But, the intakes of protein, fiber, and cholesterol were not significantly changed during the intervention period in both groups $(P>0.05)$. However, at the end of the study, between-group analysis adjusted for baseline values and confounders showed no significant differences in dietary intakes between the two groups $(P>0.05$; Table 2$)$. 
Table 2

Comparison of dietary energy and nutrient intakes between two groups of obese women with PCOS throughout the study
Thylakoid group $(\mathrm{n}=$
21)
Placebo group $(n=$
$\operatorname{MD}(95 \% \mathrm{Cl}), P$
23)

Energy (Cal)

$\begin{array}{llll}\text { Baseline } & 2346.3(399.96) & 2297.8(446.26) & \begin{array}{l}48.46(-210.31, \\ 307.24), 0.707 \star \star\end{array} \\ \text { End } & 1749.37(117.60) & 1711.3(119.84) & -0.002(-0.004, \\ & & & 0.000), 0.129 \star \star \star \\ \text { MD (95\% } & -596.96(-791.85,- & -586.55(-790.50,- & \\ \text { Cl), } P^{\star} & 402.08),<0.001 & 382.60),<0.001 & \end{array}$

Fat (g)

$\begin{array}{llll}\text { Baseline } & 84.28(13.73) & 82.30(16.00) & 1.98(-7.12,11.09), \\ & & & 0.662^{\star *}\end{array}$

MUFA (g)

$\begin{array}{llll}\text { Baseline } & 20.15(3.29) & 17.20(3.33) & \begin{array}{l}2.95(0.93,4.97), \\ \end{array} \\ \text { End } & 13.93(0.86) & 11.91(0.78) & \begin{array}{l}-0.26(-0.61,0.09), \\ \end{array} \\ & & & 0.143^{\star \star \star}\end{array}$

PUFA (g)

$\begin{array}{llll}\text { Baseline } & 41.85(6.99) & 42.81(8.42) & -0.96(-5.70,3.77), \\ & & & 0.685^{\star \star}\end{array}$

SFA, saturated fatty acid; MUFA, monounsaturated fatty acid; PUFA, polyunsaturated fatty acid.

Data are expressed as mean (standard deviation) and mean difference $(95 \% \mathrm{Cl}) . P^{*}$ : Denotes the significance of within-group changes (Paired samples t- test). $P^{\star \star}: \mathrm{P}$ values indicate comparison between groups at baseline (Independent Student's t-test for baseline). $P^{\star \star \star \star}$ : P values indicate comparison between groups based on analysis of covariance (ANCOVA) adjusted for baseline values and confounders. 


\begin{tabular}{|c|c|c|c|c|}
\hline & & $\begin{array}{l}\text { Thylakoid group }(\mathrm{n}= \\
\text { 21) }\end{array}$ & $\begin{array}{l}\text { Placebo group }(n= \\
23)\end{array}$ & $\mathrm{MD}(95 \% \mathrm{Cl}), P$ \\
\hline \multirow{3}{*}{$\begin{array}{l}\text { SFA (g) } \\
\text { Cholesterol } \\
\text { (mg) }\end{array}$} & Baseline & $15.83(2.69)$ & $14.02(2.74)$ & \multirow{2}{*}{$\begin{array}{l}1.81(0.15,3.47) \\
0.033^{\star \star}\end{array}$} \\
\hline & End & $11.04(1.26)$ & $9.72(0.72)$ & \\
\hline & $\begin{array}{l}\mathrm{MD}(95 \% \\
\mathrm{Cl}), P^{\star}\end{array}$ & $\begin{array}{l}-4.78(-6.00,-3.57),< \\
0.001\end{array}$ & $\begin{array}{l}-4.30(-5.56,-3.04),< \\
0.001\end{array}$ & $\begin{array}{l}0.04(-0.12,0.20) \\
0.585^{\star \star \star}\end{array}$ \\
\hline \multirow{9}{*}{$\begin{array}{l}\text { Carbohydrates } \\
\text { (g) }\end{array}$} & Baseline & 202.70 (39.18) & $198.20(44.45)$ & $\begin{array}{l}4.49(-21.10 \\
30.10), 0.725^{\star \star}\end{array}$ \\
\hline & End & 200.39 (27.74) & $190.62(37.42)$ & $\begin{array}{l}\text { 8.49(-8.34, 25.32), } \\
0.313^{\star \star \star}\end{array}$ \\
\hline & $\begin{array}{l}\mathrm{MD}(95 \% \\
\mathrm{Cl}), P^{\star}\end{array}$ & $\begin{array}{l}-2.30(-19.07,14.46) \\
0.777\end{array}$ & $\begin{array}{l}-7.58(-20.59,5.44) \\
0.240\end{array}$ & $\begin{array}{l}1.23(-7.78,10.25) \\
0.784^{\star \star}\end{array}$ \\
\hline & Baseline & $63.72(13.93)$ & $62.48(15.56)$ & \multirow{2}{*}{$\begin{array}{l}0.69(-0.05,1.44) \\
0.066^{\star \star \star}\end{array}$} \\
\hline & End & $65.60(4.41)$ & $64.17(4.49)$ & \\
\hline & $\begin{array}{l}\mathrm{MD}(95 \% \\
\mathrm{Cl}), P^{\star}\end{array}$ & $\begin{array}{l}\text { 1.88(-4.92, } \\
8.69), 0.570\end{array}$ & $\begin{array}{l}\text { 1.69(-5.42, } \\
8.80), 0.627\end{array}$ & $\begin{array}{l}6.41(-30.00 \\
42.83), 0.724^{\star *}\end{array}$ \\
\hline & Baseline & $333.24(57.00)$ & 326.82 (62.21) & \multirow{3}{*}{$\begin{array}{l}2.14(-2.51,6.79) \\
0.357 \star \star \star \star\end{array}$} \\
\hline & End & $240.54(16.17)$ & $235.31(16.48)$ & \\
\hline & $\begin{array}{l}\mathrm{MD}(95 \% \\
\mathrm{Cl}), P^{\star}\end{array}$ & $\begin{array}{l}-92.70(-120.55,- \\
64.85),<0.001\end{array}$ & $\begin{array}{l}-91.52(-119.64,- \\
63.39),<0.001\end{array}$ & \\
\hline \multirow[t]{3}{*}{ Fiber (g) } & Baseline & $19.16(5.52)$ & 20.96 (3.88) & \multirow{2}{*}{$\begin{array}{l}-1.81(-4.69,1.08) \\
0.213^{\star \star}\end{array}$} \\
\hline & End & $21.13(5.38)$ & 22.59 (4.54) & \\
\hline & $\begin{array}{l}\mathrm{MD}(95 \% \\
\mathrm{Cl}), P^{\star}\end{array}$ & $\begin{array}{l}1.97(-1.23,5.16) \\
0.213\end{array}$ & $\begin{array}{l}1.62(-0.52,3.76), \\
0.130\end{array}$ & $\begin{array}{l}-0.98(-4.16,2.20) \\
0.535^{\star \star \star}\end{array}$ \\
\hline \multicolumn{5}{|c|}{ SFA, saturated fatty acid; MUFA, monounsaturated fatty acid; PUFA, polyunsaturated fatty acid. } \\
\hline \multicolumn{5}{|c|}{$\begin{array}{l}\text { Data are expressed as mean (standard deviation) and mean difference }(95 \% \mathrm{Cl}) \text {. } P^{\star *} \text { : Denotes the } \\
\text { significance of within-group changes (Paired samples t- test). } P^{\star \star} \text {. P values indicate comparison } \\
\text { between groups at baseline (Independent Student's t-test for baseline). } P^{\star \star \star} \text { : P values indicate } \\
\text { comparison between groups based on analysis of covariance (ANCOVA) adjusted for baseline values } \\
\text { and confounders. }\end{array}$} \\
\hline
\end{tabular}

\section{Cardiometabolic Parameters}

Table 3 presents the cardiometabolic parameters of subjects, including abdominal obesity indicators, glycemic indices, lipid profile, blood pressure, total testosterone, and hs-CRP at baseline and after the intervention. There were no statistically significant differences in these cardiometabolic variables between the two groups at baseline $(P>0.05)$. As expected from the experimental design, all subjects in the thylakoid group and placebo group lost body weight $(-6.97 \pm .52 \mathrm{~kg}$ vs. $-3.19 \pm 0.72 \mathrm{~kg})$ at the 12th week, due to the daily energy deficit. Comparison between two groups adjusted for the baseline values 
and potential confounders revealed that there was a significant reduction in BMI in the thylakoid group compared to the placebo group after the 12-week intervention (Table 1). After 12 weeks of intervention, the serum concentrations of FBS, LDL, and HDL did not change statistically significant in both groups compared to baseline (for both variables $P>0.05)$. Changes in serum concentration of FBS $(P=0.85)$, LDL $(P=0.64)$, and HDL $(P=0.26)$ were not significant after the 12-week consumption of thylakoid than placebo; and remained unchanged after controlling for the potential confounders. The abdominal obesity parameters (WC, WHR, WHtR), HOMA-IR, LAP, and FAl, as well as fasting serum levels of insulin, total testosterone, TG, and hs-CRP decreased significantly in both thylakoid and placebo groups compared to baseline (all $P<0.05$ ). Results of the post-intervention analysis of covariance showed that these reductions remained significant after controlling for the potential confounders, including changes in physical activity, total energy intake, and weight $(P<0.001)$. Accordingly, the differences between the two groups were significant in terms of these parameters (significant reductions in the thylakoid group than the placebo group), except for FAl, which was no significant difference between the two groups $(P=0.12)$. At the end of the study, the levels of TC $(P=0.03)$, VAI $(P=0.01)$, SBP $(P=0.05)$, DBP $(P=0.01)$, SHBG ( $P$ $=0.03)$, and TyG index $(P<0.001)$ decreased significantly in the thylakoid group compared to baseline. But, these parameters were not significantly changed in the placebo group compared to baseline (all $P>$ 0.05). As shown in Table 3, results of an analysis of covariance after adjusting for the baseline values and potential confounding factors (changes in weight, physical activity, and total energy intake) revealed no significant between-group differences by the end of the study for these parameters, except for levels of TyG index and DBP, which decreased significantly in thylakoid group compared to the placebo group $(P<$ 0.05). Overall, we found that after adjustment for baseline values, age, BMI, and confounders (changes in weight, physical activity levels, and total energy intake throughout the study), daily supplementation with thylakoid had no significant effects on SBP, FAI, VAl, and serum levels of FBS, HDL, LDL,TC, and SHBG. However, this supplementation significantly lowered abdominal obesity indicators, LAP, HOMA-IR, TyG index, DBP, and serum levels of insulin, testosterone, TG, and hs-CRP. 
Table 3

Changes in cardiometabolic parameters between the thylakoid group and the placebo group at baseline and after 12 weeks of intervention.

\begin{tabular}{|c|c|c|c|c|}
\hline & & $\begin{array}{l}\text { Thylakoid group } \\
(\mathrm{n}=21)\end{array}$ & $\begin{array}{l}\text { Placebo group }(n= \\
23)\end{array}$ & $\mathrm{MD}(95 \% \mathrm{Cl}), P$ \\
\hline \multirow[t]{3}{*}{ WC (cm) } & Baseline & 108.09 (3.89) & $108.18(4.22)$ & \multirow{3}{*}{$\begin{array}{l}-0.09(-2.57,2.39) \\
0.944 * \star \\
-4.00(-5.25,-2.76) \\
<0.001^{\star \star \star}\end{array}$} \\
\hline & End & $100.31(4.58)$ & $104.46(3.75)$ & \\
\hline & 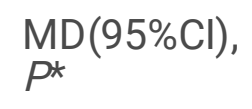 & $\begin{array}{l}-7.78(-8.92,- \\
6.65),<0.001\end{array}$ & $\begin{array}{l}-3.73(-4.33,- \\
3.12),<0.001\end{array}$ & \\
\hline \multirow[t]{3}{*}{ WHtR } & Baseline & $0.68(0.02)$ & $0.68(0.03)$ & \multirow{3}{*}{$\begin{array}{l}-0.01(-0.02,0.01) \\
0.45^{\star \star} \\
-0.02(-0.03,-0.02) \\
<0.001^{\star \star \star}\end{array}$} \\
\hline & End & $0.63(0.03)$ & $0.66(0.03)$ & \\
\hline & 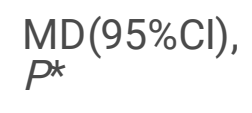 & $\begin{array}{l}-0.05(-0.05,- \\
0.04),<0.001\end{array}$ & $\begin{array}{l}-0.02(-0.03,- \\
0.02),<0.001\end{array}$ & \\
\hline \multirow[t]{3}{*}{ WHR } & Baseline & $0.92(0.01)$ & $0.93(0.01)$ & \multirow{3}{*}{$\begin{array}{l}-0.01(-0.02,-0.001) \\
\mathbf{0 . 0 2} 2^{\star \star} \\
-0.04(-0.05,-0.03) \\
<0.001^{\star \star \star}\end{array}$} \\
\hline & End & $0.87(0.03)$ & $0.92(0.02)$ & \\
\hline & 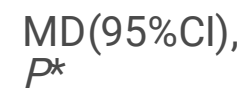 & $\begin{array}{l}-0.06(-0.06,- \\
0.04),<0.001\end{array}$ & $\begin{array}{l}-0.02(-0.02,- \\
0.01),<0.001\end{array}$ & \\
\hline \multirow[t]{3}{*}{$\mathrm{SBP}(\mathrm{mmHg})$} & Baseline & $125.95(6.64)$ & $125.48(6.79)$ & \multirow{3}{*}{$\begin{array}{l}0.47(-3.62,4.57), \\
0.82^{\star \star} \\
-3.12(-7.87,1.63), \\
0.19 \star \star \star\end{array}$} \\
\hline & End & $124.76(5.40)$ & $125.30(6.50)$ & \\
\hline & $\begin{array}{l}\mathrm{MD}(95 \% \\
\mathrm{Cl}), P^{\star}\end{array}$ & $\begin{array}{l}-1.19(-2.40 \\
0.02), 0.05\end{array}$ & $\begin{array}{l}-0.17(-0.75,0.40) \\
0.54\end{array}$ & \\
\hline \multirow[t]{3}{*}{$\mathrm{DBP}(\mathrm{mmHg})$} & Baseline & $92.01(3.66)$ & $91.80(3.07)$ & \multirow{2}{*}{$\begin{array}{l}0.20(-1.85,2.25) \\
0.84^{\star \star}\end{array}$} \\
\hline & End & $90.38(2.57)$ & $91.63(2.71)$ & \\
\hline & $\begin{array}{l}\mathrm{MD}(95 \% \\
\mathrm{Cl}), P^{\star}\end{array}$ & $\begin{array}{l}-1.63(-2.73 \\
-0.53), 0.01\end{array}$ & $\begin{array}{l}-0.17(-0.61 \\
0.25), 0.41\end{array}$ & $\begin{array}{l}-1.33(-2.19,-0.48) \\
0.003^{\star \star \star}\end{array}$ \\
\hline \multirow[t]{2}{*}{ FBS (mg/dl) } & Baseline & 93.09 (5.39) & $96.56(7.44)$ & $\begin{array}{l}-3.47(-7.46 \\
0.52), 0.086^{\star *}\end{array}$ \\
\hline & End & $92.66(4.70)$ & $96.09(6.10)$ & $\begin{array}{l}-0.28(-3.35 \\
2.79), 0.854^{\star \star \star}\end{array}$ \\
\hline \multicolumn{5}{|c|}{$\begin{array}{l}\text { DBP; diastolic blood pressure; FAl, free androgen index; FBS, fasting blood sugar; HOMA-IR: } \\
\text { homeostatic model assessment for insulin resistance; hs-CRP, HDL, high-density lipoprotein- } \\
\text { cholesterol; high-sensitivity C-reactive protein; LAP: lipid accumulation product; LDL, low-density } \\
\text { lipoprotein cholesterol; SBP, systolic blood pressure; SHBG, sex hormone binding globulin; TC, total } \\
\text { cholesterol; TG, triglycerides; TyG: Product of triacylglycerol and glucose; VAl: visceral adiposity index; } \\
\text { WC, waist circumference; WHR, waist-to-hip ratio; WHtR, Waist to height ratio. }\end{array}$} \\
\hline \multicolumn{5}{|c|}{ 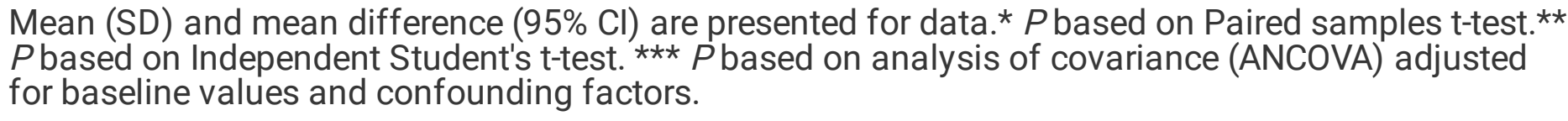 } \\
\hline
\end{tabular}




\begin{tabular}{|c|c|c|c|c|}
\hline & & $\begin{array}{l}\text { Thylakoid group } \\
(n=21)\end{array}$ & $\begin{array}{l}\text { Placebo group }(n= \\
23)\end{array}$ & $\mathrm{MD}(95 \% \mathrm{Cl}), P$ \\
\hline & $\begin{array}{l}\mathrm{MD}(95 \% \\
\mathrm{Cl}), P^{\star}\end{array}$ & $\begin{array}{l}-0.43(-1.05 \\
0.19), 0.16\end{array}$ & $\begin{array}{l}-0.48(-1.36,0.40) \\
0.27\end{array}$ & \\
\hline \multirow[t]{3}{*}{ Insulin $(\mu \mathrm{U} / \mathrm{mL})$} & Baseline & $17.97(2.45)$ & $18.63(2.33)$ & $\begin{array}{l}-0.65(-2.11 \\
0.80), 0.370^{\star *}\end{array}$ \\
\hline & End & $12.57(2.11)$ & $17.43(2.25)$ & $\begin{array}{l}-4.10(-7.31- \\
0.88), 0.01^{\star \star \star \star}\end{array}$ \\
\hline & $\begin{array}{l}\mathrm{MD}(95 \% \\
\mathrm{Cl}), P^{\star}\end{array}$ & $\begin{array}{l}-5.40(-6.25,- \\
4.55),<0.001\end{array}$ & $\begin{array}{l}-1.19(-1.56,-0.83) \\
<0.001\end{array}$ & \\
\hline \multirow[t]{3}{*}{ HOMA-IR } & Baseline & $4.14(0.69)$ & $4.43(0.60)$ & $\begin{array}{l}-0.29(-0.68 \\
0.10), 0.143^{\text {** }}\end{array}$ \\
\hline & End & $2.87(0.49)$ & $4.13(0.53)$ & $\begin{array}{l}-1.06(-1.88,-0.25) \\
0.01 \star \star \star\end{array}$ \\
\hline & $\begin{array}{l}\mathrm{MD}(95 \% \\
\mathrm{Cl}), P^{\star}\end{array}$ & $\begin{array}{l}-1.27(-1.48,- \\
1.05),<0.001\end{array}$ & $\begin{array}{l}-0.31(-0.42,-0.19) \\
<0.001\end{array}$ & \\
\hline \multirow[t]{3}{*}{ TG(mg/dl) } & Baseline & $145.57(14.86)$ & $144.09(18.23)$ & $\begin{array}{l}1.48(-8.70 \\
11.66), 0.77 * *\end{array}$ \\
\hline & End & $139.62(10.45)$ & $143.09(17.42)$ & \multirow{2}{*}{$\begin{array}{l}-4.45(-6.93 \\
-1.97), 0.001^{\star \star \star}\end{array}$} \\
\hline & $\begin{array}{l}\mathrm{MD}(95 \% \\
\mathrm{Cl}), P^{\star}\end{array}$ & $\begin{array}{l}-5.95(-9.00,- \\
2.89), 0.001\end{array}$ & $\begin{array}{l}-1.00(-2.19,0.19) \\
0.10\end{array}$ & \\
\hline \multirow[t]{3}{*}{ LDL (mg/dl) } & Baseline & $127.79(9.13)$ & $128.01(9.71)$ & $\begin{array}{l}-0.22(-5.97,5.53) \\
0.94^{\star \star}\end{array}$ \\
\hline & End & $126.60(6.50)$ & $127.40(6.86)$ & $\begin{array}{l}-0.72(-3.81,2.39) \\
0.64^{\star \star \star}\end{array}$ \\
\hline & $\begin{array}{l}\mathrm{MD}(95 \% \\
\mathrm{Cl}), P^{\star}\end{array}$ & $\begin{array}{l}-1.19(-3.92 \\
1.54), 0.37\end{array}$ & $\begin{array}{l}-0.60(-4.18,2.97) \\
0.73\end{array}$ & \\
\hline
\end{tabular}

DBP; diastolic blood pressure; FAl, free androgen index; FBS, fasting blood sugar; HOMA-IR: homeostatic model assessment for insulin resistance; hs-CRP, HDL, high-density lipoproteincholesterol; high-sensitivity C-reactive protein; LAP: lipid accumulation product; LDL, low-density lipoprotein cholesterol; SBP, systolic blood pressure; SHBG, sex hormone binding globulin; TC, total cholesterol; TG, triglycerides; TyG: Product of triacylglycerol and glucose; VAl: visceral adiposity index; WC, waist circumference; WHR, waist-to-hip ratio; WHtR, Waist to height ratio.

Mean (SD) and mean difference $(95 \% \mathrm{Cl})$ are presented for data. ${ }^{*} P$ based on Paired samples t-test.** $P$ based on Independent Student's t-test. $\star \star \star ~ P$ based on analysis of covariance (ANCOVA) adjusted for baseline values and confounding factors. 


\begin{tabular}{|c|c|c|c|c|}
\hline & & $\begin{array}{l}\text { Thylakoid group } \\
(n=21)\end{array}$ & $\begin{array}{l}\text { Placebo group }(n= \\
23)\end{array}$ & $\mathrm{MD}(95 \% \mathrm{Cl}), P$ \\
\hline \multirow[t]{3}{*}{ HDL (mg/dl) } & Baseline & $36.62(3.75)$ & $35.47(4.32)$ & \multirow{2}{*}{$\begin{array}{l}1.14(-1.33,3.61) \\
0.36^{\star \star}\end{array}$} \\
\hline & End & 36.90 (3.33) & $35.63(4.06)$ & \\
\hline & $\begin{array}{l}\mathrm{MD}(95 \% \\
\mathrm{Cl}), P^{\star}\end{array}$ & $\begin{array}{l}0.28(-1.56,2.132) \\
0.75\end{array}$ & $0.15(-2.90,3.20), 0.92$ & $\begin{array}{l}1.27(-0.99,3.54), \\
0.26^{\star \star \star}\end{array}$ \\
\hline \multirow[t]{3}{*}{$\mathrm{TC}(\mathrm{mg} / \mathrm{dl})$} & Baseline & $193.52(8.54)$ & $192.30(7.45)$ & \multirow{2}{*}{$\begin{array}{l}1.22(-3.65,6.09), \\
0.62^{\star \star}\end{array}$} \\
\hline & End & 191.43 (7.02) & 191.65 (6.83) & \\
\hline & $\begin{array}{l}\mathrm{MD}(95 \% \\
\mathrm{Cl}), P^{\star}\end{array}$ & $\begin{array}{l}-2.10(-4.03,- \\
0.16), 0.03\end{array}$ & $\begin{array}{l}-0.65(-1.54,0.24) \\
0.14\end{array}$ & $\begin{array}{l}-1.15(-2.98,0.68), \\
0.21^{\star \star \star}\end{array}$ \\
\hline \multirow[t]{3}{*}{ Tyg index } & Baseline & $8.81(0.11)$ & $8.84(0.13)$ & $\begin{array}{l}-0.02(-0.10,0.54) \\
0.56^{\star \star}\end{array}$ \\
\hline & End & $8.77(0.09)$ & $8.83(0.13)$ & 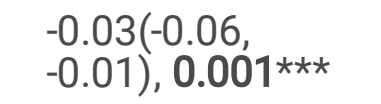 \\
\hline & $\begin{array}{l}\mathrm{MD}(95 \% \\
\mathrm{Cl}), P^{\star}\end{array}$ & $\begin{array}{l}-0.04(-0.06,- \\
0.02),<0.001\end{array}$ & $\begin{array}{l}-0.01(-0.02,0.003) \\
0.11\end{array}$ & \\
\hline \multirow[t]{3}{*}{ LAP } & Baseline & $82.34(10.62)$ & $82.21(16.23)$ & $\begin{array}{l}0.12(-8.31,8.56) \\
0.98^{\star \star}\end{array}$ \\
\hline & End & $66.64(8.21)$ & $75.51(14.13)$ & $\begin{array}{l}-8.65(-10.69 \\
-6.61),<0.001^{\star \star \star \star}\end{array}$ \\
\hline & $\begin{array}{l}\mathrm{MD}(95 \% \\
\mathrm{Cl}), P^{\star}\end{array}$ & $\begin{array}{l}-15.70(-18.42 \\
-12.98),<0.001\end{array}$ & $\begin{array}{l}-6.70(-8.04,-5.37),< \\
0.001\end{array}$ & \\
\hline \multirow[t]{3}{*}{ VAl } & Baseline & $3.46(0.53)$ & $3.53(0.61)$ & $\begin{array}{l}-0.08(-0.42 \\
0.27), 0.66^{\star \star}\end{array}$ \\
\hline & End & $3.21(0.42)$ & $3.45(0.55)$ & $\begin{array}{l}-0.20(-0.46,0.60) \\
0.13^{\star \star \star}\end{array}$ \\
\hline & $\begin{array}{l}\mathrm{MD}(95 \% \\
\mathrm{Cl}), P^{\star}\end{array}$ & $\begin{array}{l}-0.25(-0.43 \\
-0.07), 0.01\end{array}$ & $-0.09(-0.37,0.20), 0.53$ & \\
\hline
\end{tabular}

DBP; diastolic blood pressure; FAl, free androgen index; FBS, fasting blood sugar; HOMA-IR: homeostatic model assessment for insulin resistance; hs-CRP, HDL, high-density lipoproteincholesterol; high-sensitivity C-reactive protein; LAP: lipid accumulation product; LDL, low-density lipoprotein cholesterol; SBP, systolic blood pressure; SHBG, sex hormone binding globulin; TC, total cholesterol; TG, triglycerides; TyG: Product of triacylglycerol and glucose; VAl: visceral adiposity index; WC, waist circumference; WHR, waist-to-hip ratio; WHtR, Waist to height ratio.

Mean (SD) and mean difference $(95 \% \mathrm{Cl})$ are presented for data. ${ }^{*} P$ based on Paired samples t-test.** $P$ based on Independent Student's t-test. $\star \star \star ~ P$ based on analysis of covariance (ANCOVA) adjusted for baseline values and confounding factors. 


\section{Thylakoid group \\ ( $n=21)$ \\ Placebo group $(\mathrm{n}=$ \\ MD (95\% Cl), $P$ \\ 23)}

Total

testosterone

( $\mathrm{ng} / \mathrm{ml}$ )

$\begin{array}{llll}\text { Baseline } & 0.65(0.06) & 0.69(0.08) & \begin{array}{l}-0.03(-0.08, \\ \end{array} \\ \text { End } & 0.59(0.03) & 0.66(0.07) & -0.12^{\star \star} \\ & & & 0.06(-0.12,- \\ & & & 0.03^{\star \star \star}\end{array}$

SHBG (nmol/L)

$\begin{array}{lll}\mathrm{MD}(95 \% & -0.06(-0.08,-0.04),< & -0.03(-0.03,-0.02) \\ \mathrm{Cl}), P^{\star} & 0.001 & \mathbf{0 . 0 0 1} \\ \text { Baseline } & 25.83(1.12) & 25.76(1.02) \\ \text { End } & 26.28(1.13) & 25.97(0.79) \\ \text { MD (95\% } & 0.45(0.06,0.84), & 0.22(-0.01,0.44), \\ \mathrm{Cl}), P^{\star} & \mathbf{0 . 0 2 6} & 0.057\end{array}$

FAI
Baseline
$8.82(0.98)$
$9.28(1.07)$
$-.46(-1.09,0.16)$,
End
$7.87(0.48)$
$8.83(0.94)$
$0.14 \star \star$

$0.72(-0.58$

$0.72), 0.824^{\star \star}$

$-0.52(-2.02$ $0.97), 0.483^{\star \star \star}$
End $\quad 7.87(0.48)$
$-0.95(-1.25,-0.66)$,
MD $(95 \%$
$\mathrm{Cl}), P^{\star}$
$<0.001$
$-0.45(-0.58,-0.32),<$
0.001

hs-CRP (mg/L)

$\begin{array}{llll}\text { Baseline } & 3.67(0.26) & 3.70(0.27) & \begin{array}{l}-0.03(-0.19, \\ 0.13), 0.69 * *\end{array} \\ \text { End } & 3.11(0.17) & 3.64(0.23) & -0.51(-0.56, \\ & & & -0.46),<0.001 \text { *** } \\ \text { MD (95\% } & -0.57(-0.63,-0.50), & -0.07(-0.10,-0.03),< & \\ \text { Cl), } P^{\star} & <\mathbf{0 . 0 0 1} & \mathbf{0 . 0 0 1}\end{array}$

DBP; diastolic blood pressure; FAl, free androgen index; FBS, fasting blood sugar; HOMA-IR:

homeostatic model assessment for insulin resistance; hs-CRP, HDL, high-density lipoproteincholesterol; high-sensitivity C-reactive protein; LAP: lipid accumulation product; LDL, low-density lipoprotein cholesterol; SBP, systolic blood pressure; SHBG, sex hormone binding globulin; TC, total cholesterol; TG, triglycerides; TyG: Product of triacylglycerol and glucose; VAl: visceral adiposity index; WC, waist circumference; WHR, waist-to-hip ratio; WHtR, Waist to height ratio.

Mean (SD) and mean difference $(95 \% \mathrm{Cl})$ are presented for data. ${ }^{*} P$ based on Paired samples t-test.** $P$ based on Independent Student's t-test. $\star \star \star ~ P$ based on analysis of covariance (ANCOVA) adjusted for baseline values and confounding factors. 


\section{Discussion}

The present clinical trial investigated the effects of 12 weeks intake of thylakoid-rich spinach extract on the cardiometabolic risk factors in obese women with PCOS under a calorie-restricted diet for the first time. The results of this study showed that thylakoid-rich spinach extract supplementation with the daily dose of $5 \mathrm{~g}$ for 12 weeks, concurrent with a low-calorie diet could significantly decrease the body weight, BMI, abdominal obesity indicators (WC, WHR, WHtR), diastolic blood pressure, LAP, HOMA-IR, TyG index, serum levels of insulin, TG, testosterone, and hs-CRP. We observed significant decreases in VAI, FAI, TC, and SBP, as well as a significant increase in SHBG level in the intervention group compared to the baseline. But, these changes were not significant compared to the control group after adjusting for potential confounders. Serum concentrations of FBS, LDL, and HDL did not change significantly in both groups compared to the baseline and did not differ significantly between the two groups (Table 3). During this study, due to receiving a low-calorie diet by all participants, intakes of energy and macronutrients changed significantly compared to baseline. But, these changes in the intervention group were not significant compared to the placebo group (Table 2). To our knowledge, clinical trials evaluating the effects of thylakoid-rich spinach extract supplementation in women with PCOS do not exist. After adjusting for confounders, we found that both general and central or abdominal obesity-related indicators significantly decreased in the thylakoid consumers compared to the placebo recipients. BMI, as an assessment tool for general obesity, WC, as a screening instrument for determining abdominal obesity, WHR, as an instrument for assessing central obesity and visceral fat, and WHtR, as an anthropometric indicator for assessing central adiposity, were evaluated $[29,30]$. Our findings regarding the reductions in body weight, BMI, WC, WHR, and WHtR are in agreement with the findings of a recent systematic review of the anti-obesity effects of the thylakoid-rich spinach extract [15], and other studies [16-18, 31-34] that demonstrated weight loss, body fat and body mass reductions following including thylakoid-rich spinach extract into the diet. Several proposed mechanisms involved in these effects are as follows: inhibition of the pancreatic lipase/co-lipase activity, consequently, retarding the digestion and absorption of dietary fat; hence, post-prandial high-fat content in the small intestinal lumen curbs hunger and stimulates satiety signals including, the gut-derived satiety hormone cholecystokinin (CCK)and glucagon-like peptide-1(GLP-1) as well as the adipose-derived satiety hormone leptin. Moreover, a significant reduction in serum levels of ghrelin, a stomach-derived hunger hormone, was demonstrated. Resultant satiety promotion and suppressed appetite to eat contribute to reduced food intake and subsequent weight loss in subjects[16, 17, 21, 31, 32, 34-36]. In our study, there were no significant differences between the intervention group and the placebo group regarding the intake of energy and dietary nutrients. Our findings were in agreement with the previous studies $[17,32]$ in which indicated no significant changes in total calorie and nutrient intakes of thylakoid consumers in trials, and food intake at the next meal following thylakoid intake was not different between the placebo and the thylakoid groups. Thus, the exact mechanism of thylakoid affecting anthropometric indices should be explored. The present study indicated that consumption of $5 \mathrm{~g}$ thylakoid-rich spinach extract for 12 weeks significantly decreased insulin and HOMA-IR, but did not affect FBS in obese women with PCOS. This was consistent with the results of the study by Köhnke et al.; they reported a $37 \%$ reduction in the insulin levels in the thylakoid 
group compared to the control group, without significant changes in blood glucose levels between the two groups[31]. Significant decreases in insulin levels in thylakoid consumers compared to controls, without considerable changes in glucose level probably, suggest an elevated insulin-stimulated glucose uptake in cells due to increased insulin sensitivity as a result of thylakoid supplementation in our study. Considering the weight loss and central obesity reduction, as well as insulin sensitivity improvement and insulin resistance attenuation following thylakoid supplementation without changes in glucose concentration in our study, which has also been demonstrated in some studies [17, 32], thus, it presents good implications of spinach thylakoid for obesity treatment. On the contrary, regarding glucose levels, multiple animal studies reported the hypoglycemic action of spinach-derived thylakoids [23, 37-39]. Park et al. found that spinach extract inhibited intestinal a-glucosidase in vitro, and the digestion of disaccharides (-19.6\%), hence, by lowering the uptake of dietary glucose, glycemia might be improved [40]. In another study, intake of $0.5 \mathrm{~g} / \mathrm{kg}$ body weight of spinach thylakoid in a single dose, led to blood glucose suppressed after an oral glucose tolerance test, without changes in insulin levels in pigs [39]. The discrepancy between the findings of studies might result from the differences in type and dosages of spinach thylakoids, duration of intervention, design of the study, and acute or chronic administration of the spinach thylakoids. There are some probable mechanisms for the beneficial effects of thylakoid-rich spinach extract on glucose metabolism as follows: reducing intestinal uptake of glucose by localization of thylakoids as large complex structures onto the mucosa and also, by binding to the starch and/or amylase, increasing CCK and GLP-1 secretions, and postponing gastric emptying. Additionally, the antiobesity and beneficial effects of thylakoid-rich spinach extract on anthropometric indices might play a crucial role in the improvement of glycemic parameters $[23,38,41]$. The findings of the current study demonstrated that after the 12-week intervention, total testosterone levels decreased significantly in both groups compared to baseline. But, these changes were significantly different between the two groups, and spinach-derived thylakoid supplementation contributed to a significant reduction in total testosterone levels, even after adjusting for all potential confounders. In this regard, no other study is available investigating the effect of spinach thylakoids supplementation on testosterone levels and hyperandrogenism status. However, our findings are in accord with reports elsewhere on weight loss in PCOS[13, 42]. It has been demonstrated that high testosterone in women with PCOS is often associated with increased adiposity and insulin resistance. Furthermore, insulin directly stimulates androgen synthesis by the theca cell. Therefore, the improvement of insulin sensitivity and the resultant decrease in circulating insulin could decrease testosterone levels, as previously reported, that improvement in insulin resistance through weight loss or the use of insulin-sensitizing drugs leads to a decrease in hyperandrogenemia $[43,44]$. For the first time, we observed that thylakoid-rich spinach extract with a hypocaloric diet decreased DBP and serum levels of hs-CRP, without effect on the SBP in obese women with PCOS after 12 weeks. There are limited studies with contradictory findings on the effects of spinach extract contained thylakoids on the inflammatory status and blood pressure. Rebello et al. reported that $5 \mathrm{~g}$ of spinach extract rich of thylakoid had no significant effect on the hs-CRP levels in overweight or obese males and females. In this study, each participant was tested with one-time thylakoid-rich spinach extract ingestion on 2 days, and the hs-CRP level evaluated two hours after lunch [32].Moreover, Stenblom et al. reported that the concentrations of TNF-a decreased significantly from 0 to 240 min after the 
thylakoid supplementation in healthy overweight women. Blood samples were evaluated over a 4-h period [35]. It seems that the differences in duration of intervention or design of the study, individual differences, and baseline values may result in different findings. PCOS is associated with increased hs-CRP concentration. It is demonstrated that hs-CRP be as an indicator to identify the risk of cardiovascular events, and a high level of hs-CRP, as a marker of chronic inflammation, was associated with the risk of hypertension development $[45,46]$. Previous studies revealed the documented potential roles of spinach extract in the restoration of these conditions by suppressing reactive oxygen species(ROS), lowering oxidative damage, and inhibiting NF-KB activation and consequent pro-inflammatory markers $[15,47,48]$. Lipid components of thylakoid mainly, galactosyldiacylglycerols, have shown anti-inflammatory activities in several studies $[49,50]$. Considering, hyperandrogenism may be the initiator of chronic low-grade inflammation, and increased abdominal adiposity contributes to the inflammatory load in PCOS, the reducing effect of thylakoid-rich spinach extract on the hs-CRP level can be explained by the decrease in abdominal obesity and insulin resistance, which causes a decrease in hyperandrogenism by decrease in LH-mediated androgen secretion and reduced peripheral aromatization [51]. The most common pigment of thylakoid, chlorophyll, is rich in magnesium. According to previous studies, magnesium-rich foods can help to lower hypertension; so, thylakoid-rich spinach extract because of its high magnesium content, as the central atom of the chlorophyll molecule, might exert antihypertensive effects through providing a large amount of this mineral [52].Additionally, it is reported that spinach extract, as the richest source of nitrate, shows cardioprotective effects through inducing an increase in postprandial plasma nitrate and nitrite concentrations and lowering blood pressure. It is hypothesized that these effects are mediated by alterations in oxidative stress. In this regard, the increase in NO and its bioavailability, lead to the inhibition of adhesion molecules expression and ROS production suppression, with consequent action on vascular inflammatory condition [53]. Furthermore, it may exert antihypertensive effects by modulating body weight and insulin resistance in this trial. As we know, no reports are available indicating the effects of spinach thylakoid supplementation on blood pressure and inflammatory status in women with PCOS. Regarding lipid profile, we found that supplementation with thylakoid-rich spinach extract ( $5 \mathrm{~g} /$ day for 12 weeks) decreased significantly serum TG concentration, even after adjusting for confounders and baseline values. But, other lipid parameters (TC, LDL, and HDL) did not change significantly. Other major findings of our study are the beneficial effects of thylakoid-rich spinach extract supplementation on the LAP and TyG index, which decreased significantly. However, the changes in VAl were not significant between the two groups at the end of the study. According to several studies, three novel insulin resistance-related markers such as the VAI, LAP, and TyG have shown high accuracy for IR and had higher sensitivity for prediabetes/diabetes discrimination in the general population [28]. These three indices were computed by anthropometric and laboratory parameters (TG, HDL, FBS). Thus, insignificant changes in VAl correspond with insignificant changes in HDL concentrations, and significant reductions in TyG and LAP correspond with the significant reductions in TG concentrations. Contrary to our findings, previous clinical studies showed that thylakoid supplementation is beneficial in reducing LDL cholesterol $[17,54]$. A number of animal studies revealed the potential of the spinach extract containing thylakoids to lower blood triglycerides $[37,55,56]$. Due to the lack of studies regarding the effects of spinach-derived thylakoids on lipid metabolism, the mechanism by which thylakoid-rich spinach extract might affect lipid 
profile are still unknown. The existing evidence shows that the prebiotic effect of spinach thylakoids, and hence, modulation of gut microbiota may be involved in the lipid-lowering properties of the thylakoid-rich spinach extract $[38,57]$. In this regard, it is demonstrated that spinach thylakoid consumption induces fatty acid oxidation and inhibits de novo synthesis of lipids through increasing the generation of shortchain fatty acids (SCFAs). Additionally, both population and diversion of gut microbiota were affected by the intake of spinach thylakoids. The bacterium Lactobacillus reuteri was increased in the distal ileum in the receiving thylakoids group. It is reported that Lactobacillus reuteri can reduce serum cholesterol levels $[38,58,59]$. However, further studies are needed to investigate the prebiotic effects of thylakoid-rich spinach extract and its effect on the gut microbiota, particularly those with cardio-metabolic benefit properties.

This study, as the first clinical trial, had several strengths including, monitoring the patients' diets by designing calorie-restricted dietary plans with a focus on amount and type of the macronutrients, and individual preferences, tracking physical activities and dietary intakes before, through, and after the intervention. Other principal strengths of this study were: a low drop-out rate and a high compliance rate of the participants to the treatment in groups, frequent visits and phone calls, the double-blindness of this study, and the adjusting of measured biochemical parameters for the known confounding factors. Limitations of our study include relatively small sample size, the absence of a follow-up evaluation of ovarian masses by sonographic assessment, and not testing for a dose-response relationship between thylakoid intake and appeared changes in the measured parameters. In this trial, the appetite and desire to eat in a short duration were not assessed. We did not assess the prebiotic effects of spinach extract and also, the gut microbiota of PCOS patients.

\section{Conclusions}

In conclusion, the present trial, for the first time, revealed that supplementation with $5 \mathrm{~g} /$ day thylakoid-rich spinach extract in combination with calorie-restrictive diet for 12 weeks in obese PCOS women could significantly improve abdominal obesity parameters and insulin resistance, which are the key components of the therapeutic plan for obese women with PCOS. Along with these changes, DBP and serum levels of TG, testosterone, and hs-CRP decreased significantly compared to the calorie-restrictive diet alone. These data suggest that the thylakoid-rich spinach extract supplementation in combination with a calorie-restrictive diet might be applied as an adjunct intervention in conjunction with other pharmacological procedures aimed at achieving improvement in cardiometabolic disturbances in obese women with PCOS. However, data in this regard were limited and further investigations organized as placebo-controlled trials with larger sample size and longer duration are proposed.

\section{Abbreviations}

ANCOVA, Analysis of covariance; BMI, body mass index; CCK, Cholecystokinin; $\mathrm{Cl}$, confidence interval; CVs, Coefficient variances; FAI, Free androgen index; DBP, diastolic blood pressure; FBS, fasting blood sugar; GLP-1, glucagon-like peptide-1; HC, hip circumference; HDL-c, high-density lipoprotein-cholesterol; 
HOMA-IR, homeostasis model assessment of insulin resistance; hs-CRP, IR, insulin resistance; LAP, lipid accumulation product; LDL-C, low-density lipoprotein cholesterol; LH, luteinizing hormone; MUFA, monounsaturated fatty acid; NF-kB, nuclear factor kappa B; NO, nitric oxide; OCP, Oral contraceptive pill; PCOS, polycystic ovary syndrome; PUFA, polyunsaturated fatty acid; REE, Resting energy expenditure; ROS, reactive oxygen species; SBP, systolic blood pressure; SCFAs, short-chain fatty acids; SD, standard deviation; SFA, saturated fatty acid; SHBG, sex hormone-binding globulin; TC, total cholesterol; TG, triglycerides; TyG, triglyceride glucose index; VAl, visceral adiposity index; WC, Waist circumference; WHR, waist-to-hip ratio; WHtR, Waist to height ratio.

\section{Declarations}

\section{Ethics approval and consent to participate}

The protocol was approved by the ethics committee of research vice-chancellor of Tabriz University of Medical Sciences, Tabriz, Iran (Ethics code: IR.TBZMED.REC.1397.447). After being given a full explanation of the study procedures, written informed consent was obtained from all patients.

\section{Consent for publication}

Not applicable.

\section{Availability of data and materials}

Data that support the findings of this study are available from the corresponding author upon reasonable request.

\section{Competing interests}

All authors declared that they have no potential conflict of interest.

\section{Funding}

The study was financially supported by the grant of Vice-Chancellor for Research, Tabriz University of Medical Sciences, Tabriz, Iran under the registration code of 59918 and the grant of Iran National Science Foundation (INSF) for its financial support (Grant number \#96013888).

\section{Authors' contributions}


FPFT: Contributed to the study conception and design, and data collection and analysis, and drafting of the manuscript. MA: Participated in study design and contributed to the interpretation of data, revising the paper critically, and giving final approval. MV: Contributed to sampling, diagnosis, confirmation of PCOS, and enrollment of patients and data gathering from study participants, and also contributed to completing this clinical trial. SH: Contributed to preparing of thylakoid supplement from spinach leaves and collecting of data. All authors have given final approval of the version to be published.

\section{Acknowledgement}

We sincerely thank all PCOS women who participated in this clinical trial. The study was a part of Fatemeh Pourteymour Fard Tabrizi's Ph.D. thesis that was financially supported by a grant from ViceChancellor for Research, Tabriz University of Medical Sciences, Tabriz, Iran under the code of 59918. We would also like to thank the Iran National Science Foundation (INSF) for its financial support (Grant number \#96013888).

\section{References}

1. Fauser BCJM, Tarlatzis BC, Rebar RW, Legro RS, Balen AH, Lobo R, et al. Consensus on women's health aspects of polycystic ovary syndrome (PCOS): The Amsterdam ESHRE/ASRM-Sponsored 3rd PCOS Consensus Workshop Group. Fertil Steril. 2012;97:28-38.

2. Ding T, Hardiman PJ, Petersen I, Wang FF, Qu F, Baio G. The prevalence of polycystic ovary syndrome in reproductiveaged women of different ethnicity: A systematic review and meta-analysis. Oncotarget. 2017;8:96351-8.

3. Jalilian A, Kiani F, Sayehmiri F, Sayehmiri K, Khodaee Z, Akbari M. Prevalence of polycystic ovary syndrome and its associated complications in Iranian women: A meta-analysis. Int J Reprod Biomed. 2015;13:591-604.

4. Daniilidis A, Dinas K. Long term health consequences of polycystic ovarian syndrome: A review analysis. Hippokratia. 2009;13:90-2.

5. Legro RS, Arslanian SA, Ehrmann DA, Hoeger KM, Murad MH, Pasquali R, et al. Diagnosis and treatment of polycystic ovary syndrome: An endocrine society clinical practice guideline. J Clin Endocrinol Metab. 2013;98:4565-92.

6. Catteau-Jonard S, Dewailly D. Pathophysiology of polycystic ovary syndrome: the role of hyperandrogenism. Front Horm Res. 2013;40:22-7.

7. Escobar-Morreale HF. The role of androgen excess in metabolic dysfunction in women: Androgen excess and female metabolic dysfunction. Adv Exp Med Biol. 2017;1043:597-608.

8. Guastella E, Longo RA, Carmina E. Clinical and endocrine characteristics of the main polycystic ovary syndrome phenotypes. Fertil Steril. 2010;94:2197-201. 
9. Lim SS, Davies MJ, Norman RJ, Moran LJ. Overweight, obesity and central obesity in women with polycystic ovary syndrome: A systematic review and meta-analysis. Hum Reprod Update. 2012;18:618-37.

10. Liu Q, Xie Y jie, Qu L hua, Zhang M xia, Mo Z cheng. Dyslipidemia involvement in the development of polycystic ovary syndrome. Taiwan J Obstet Gynecol. 2019;58:447-53.

11. Blagojević IP, Ignjatović S, MacUt D, Kotur-Stevuljević J, Božić-Antić I, Vekić J, et al. Evaluation of a Summary Score for Dyslipidemia, Oxidative Stress and Inflammation (The Doi Score) in Women with Polycystic Ovary Syndrome and its Relationship with Obesity. J Med Biochem. 2018;37:476-85.

12. Teede HJ, Misso ML, Costello MF, Dokras A, Laven J, Moran L, et al. Recommendations from the international evidence-based guideline for the assessment and management of polycystic ovary syndrome. Hum Reprod. Oxford University Press; 2018;33:1602-18.

13. Panidis D, Farmakiotis D, Rousso D, Kourtis A, Katsikis I, Krassas G. Obesity, weight loss, and the polycystic ovary syndrome: effect of treatment with diet and orlistat for 24 weeks on insulin resistance and androgen levels. Fertil Steril. 2008;89:899-906.

14. Brett EM. Pharmacotherapy for weight management. Bariatr Endocrinol. 2018;395-411.

15. Pourteymour Fard Tabrizi F, Abbasalizad Farhangi M. A Systematic Review of the Potential Effects of Thylakoids in the Management of Obesity and Its Related Issues. Food Rev Int. 2020;in Press.

16. Albertsson PÅ, Köhnke R, Emek SC, Mei J, Rehfeld JF, Åkerlund HE, et al. Chloroplast membranes retard fat digestion and induce satiety: Effect of biological membranes on pancreatic lipase/colipase. Biochem J. 2007;401:727-33.

17. Montelius C, Erlandsson D, Vitija E, Stenblom EL, Egecioglu E, Erlanson-Albertsson C. Body weight loss, reduced urge for palatable food and increased release of GLP-1 through daily supplementation with green-plant membranes for three months in overweight women. Appetite. 2014;81:295-304.

18. Erlanson-Albertsson C, Albertsson PÅ. The Use of Green Leaf Membranes to Promote Appetite Control, Suppress Hedonic Hunger and Loose Body Weight. Plant Foods Hum Nutr. 2015;70:281-90.

19. Rotterdam ESHRE/ASRM-Sponsored PCOS Consensus Workshop Group. Revised 2003 consensus on diagnostic criteria and long-term health risks related to polycystic ovary syndrome. Fertil Steril. 2004;81:19-25.

20. Stenblom E-L, Montelius C, Erlandsson D, Skarping L, Fransson M, Egecioglu E, et al. Decreased Urge for Palatable Food after a Two-month Dietary Intervention with Green-plant Membranes in Overweight Women. J Obes Weight Loss Ther. 2014;04:1-8.

21. Stenblom E-L, Egecioglu E, Landin-Olsson M, Erlanson-Albertsson C. Consumption of thylakoid-rich spinach extract reduces hunger, increases satiety and reduces cravings for palatable food in overweight women. Appetite. 2015;91:209-19.

22. Frankenfield DC, Rowe WA, Smith JS, Cooney RN. Validation of several established equations for resting metabolic rate in obese and nonobese people. J Am Diet Assoc. 2003;103:1152-9.

23. Montelius C, Gustafsson K, Weström B, Albertsson PÅ, Emek SC, Rayner M, et al. Chloroplast thylakoids reduce glucose uptake and decrease intestinal macromolecular permeability. Br J Nutr. 
2011;106:836-44.

24. Emek SC, Szilagyi A, Åkerlund HE, Albertsson PÅ, Köhnke R, Holm A, et al. A large scale method for preparation of plant thylakoids for use in body weight regulation. Prep Biochem Biotechnol. 2010;40:13-27.

25. Friedewald WT, Levy RI, Fredrickson DS. Estimation of the concentration of low-density lipoprotein cholesterol in plasma, without use of the preparative ultracentrifuge. Clin Chem. 1972;18:499-502.

26. Pisprasert V, Ingram KH, Lopez-Davila MF, Munoz AJ, Garvey WT. Limitations in the use of indices using glucose and insulin levels to predict insulin sensitivity: Impact of race and gender and superiority of the indices derived from oral glucose tolerance test in African Americans. Diabetes Care. 2013;36:845-53.

27. Azziz R, Carmina E, Dewailly D, Diamanti-Kandarakis E, Escobar-Morreale HF, Futterweit W, et al. The Androgen Excess and PCOS Society criteria for the polycystic ovary syndrome: the complete task force report. Fertil Steril. 2009;91:456-88.

28. Ahn N, Baumeister SE, Amann U, Rathmann W, Peters A, Huth C, et al. Visceral adiposity index (VAI), lipid accumulation product (LAP), and product of triglycerides and glucose (TyG) to discriminate prediabetes and diabetes. Sci Rep. 2019;9:1-11.

29. Ashtary-Larky D, Daneghian S, Alipour M, Rafiei H, Ghanavati M, Mohammadpour R, et al. Waist circumference to height ratio: Better correlation with fat mass than other anthropometric indices during dietary weight loss in different rates. Int J Endocrinol Metab. 2018;16.

30. Thu Tran NT, Blizzard CL, Luong KN, Van Truong N Le, Tran BQ, Otahal P, et al. The importance of waist circumference and body mass index in cross-sectional relationships with risk of cardiovascular disease in Vietnam. PLoS One. 2018;13:e0198202.

31. Kohnke R, Lindbo A, Larsson T, Lindqvist A, Rayner M, Emek SC, et al. Thylakoids promote release of the satiety hormone cholecystokinin while reducing insulin in healthy humans. Scand $J$ Gastroenterol. 2009;44:712-9.

32. Rebello CJ, Chu J, Beyl R, Edwall D, Erlanson-Albertsson C, Greenway FL. Acute Effects of a Spinach Extract Rich in Thylakoids on Satiety: A Randomized Controlled Crossover Trial. J Am Coll Nutr. 2015;34:470-7.

33. Köhnke R, Lindqvist A, Göransson N, Emek SC, Albertsson PA, Rehfeld JF, Hultgårdh-Nilsson A E-AC. Thylakoids suppress appetite by increasing cholecystokinin resulting in lower food intake and body weight in high-fat fed mice. Phyther Res. 2009;23:1778-83.

34. Maljaars J, Peters HPF, Masclee AM. The gastrointestinal tract: Neuroendocrine regulation of satiety and food intake. Aliment Pharmacol Ther. 2007;26:241-50.

35. Stenblom EL, Montelius C, Östbring K, Håkansson M, Nilsson S, Rehfeld JF, et al. Supplementation by thylakoids to a high carbohydrate meal decreases feelings of hunger, elevates CCK levels and prevents postprandial hypoglycaemia in overweight women. Appetite. 2013;68:118-23.

36. Panda V, Shinde P. Appetite suppressing effect of Spinacia oleracea in rats: Involvement of the short term satiety signal cholecystokinin. Appetite. 2017;113:224-30. 
37. Köhnke R, Lindqvist A, Göransson N, Emek SC, Albertsson P-Å, Rehfeld JF, et al. Thylakoids Suppress Appetite by Increasing Cholecystokinin Resulting in Lower Food Intake and Body Weight in High-fat Fed Mice. Phytother Res. 2009;23:1778-83.

38. Montelius C, Osman N, Weström B, Ahrné S, Molin G, Albertsson PÅ, et al. Feeding spinach thylakoids to rats modulates the gut microbiota, decreases food intake and affects the insulin response. J Nutr Sci. 2013;2:1-9.

39. Montelius C, Szwiec K, Kardas M, Lozinska L, Erlanson-Albertsson C, Pierzynowski S, et al. Dietary thylakoids suppress blood glucose and modulate appetite-regulating hormones in pigs exposed to oral glucose tolerance test. Clin Nutr. 2014;33:1122-6.

40. Park JH, Kim RY, Park E. Antidiabetic activity of fruits and vegetables commonly consumed in Korea: Inhibitory potential against a-glucosidase and insulin-like action in vitro. Food Sci Biotechnol. Springer; 2012;21:1187-93.

41. Emek SC, Åkerlund HE, Clausén M, Ohlsson L, Weström B, Erlanson-Albertsson C, et al. Pigments protect the light harvesting proteins of chloroplast thylakoid membranes against digestion by gastrointestinal proteases. Food Hydrocoll. 2011;25:1618-26.

42. Phy Ali M JL. Low Starch/Low Dairy Diet Results in Successful Treatment of Obesity and CoMorbidities Linked to Polycystic Ovary Syndrome (PCOS). J Obes Weight Loss Ther. 2015;05.

43. Diamanti-Kandarakis $E$, Dunaif $A$. Insulin resistance and the polycystic ovary syndrome revisited: An update on mechanisms and implications. Endocr Rev. 2012;33:981-1030.

44. Zhang B, Wang J, Shen S, Liu J, Sun J, Gu T, et al. Association of Androgen Excess with Glucose Intolerance in Women with Polycystic Ovary Syndrome. Biomed Res Int. 2018;2018:6869705.

45. Jayedi A, Rahimi K, Bautista LE, Nazarzadeh M, Zargar MS, Shab-Bidar S. Inflammation markers and risk of developing hypertension: A meta-analysis of cohort studies. Heart. 2019;105:686-92.

46. Boulman N. Levy Y. Leiba R. Shachar S. Linn R. Zinder O. Blumenfeld Z, Boulman N. LY, Boulman $\mathrm{N}$, Levy Y, Leiba R, Shachar S, et al. Increased C-reactive protein levels in the polycystic ovary syndrome: a marker of cardiovascular disease. J Clin Endocrinol Metab. 2004;89:2160-5.

47. Roberts JL, Moreau R. Functional properties of spinach (Spinacia oleracea L.) phytochemicals and bioactives. Food Funct. 2016;7:3337-53.

48. Nagar A, Shukla AK, Bigoniya P. Anti-inflammatory potential of Spinacia oleracea leaf extract. J Nat Pharm. 2011;2:80-7.

49. Kobayashi K. Role of membrane glycerolipids in photosynthesis, thylakoid biogenesis and chloroplast development. J Plant Res. 2016;129:565-80.

50. Bruno A, Rossi C, Marcolongo G, Di Lena A, Venzo A, Berrie CP, et al. Selective in vivo antiinflammatory action of the galactolipid monogalactosyldiacylglycerol. Eur J Pharmacol. 2005;524:159-68.

51. González F. Inflammation in Polycystic Ovary Syndrome: Underpinning of insulin resistance and ovarian dysfunction. Steroids. 2012;77:300-5. 
52. Lee S, Park HK, Son SP, Lee CW, Kim IJ, Kim HJ. Effects of oral magnesium supplementation on insulin sensitivity and blood pressure in normo-magnesemic nondiabetic overweight Korean adults. Nutr Metab Cardiovasc Dis. 2009;19:781-8.

53. Jovanovski E, Bosco L, Khan K, Au-Yeung F, Ho H, Zurbau A, et al. Effect of Spinach, a High Dietary Nitrate Source, on Arterial Stiffness and Related Hemodynamic Measures: A Randomized, Controlled Trial in Healthy Adults. Clin Nutr Res. 2015;4:160.

54. Stenblom EL, Montelius C, Erlandsson D, Skarping L, Fransson M et al. Decreased Urge for Palatable Food after a Two-month Dietary Intervention with Green-plant Membranes in Overweight Women. J Obes Weight Loss Ther. OMICS International; 2014;04:1-8.

55. Ko SH, Park JH, Kim SY, Lee SW, Chun SS, Park E. Antioxidant effects of spinach (Spinacia oleracea L.) supplementation in hyperlipidemic rats. Prev Nutr Food Sci. 2014;19:19-26.

56. V. Gomathi, B. Jayakar, R. Kothai, G. Ramakrishnan. Antidiabetic activity of leaves of Spinacia oleracea Linn. in Alloxaninduced diabetic rats. J Chem Pharm Res. 2010;2:266-74.

57. Stenblom EL, Weström B, Linninge C, Bonn P, Farrell M, Rehfeld JF, et al. Dietary green-plant thylakoids decrease gastric emptying and gut transit, promote changes in the gut microbial flora, but does not cause steatorrhea. Nutr Metab. 2016;13:67.

58. Den Besten G, Van Eunen K, Groen AK, Venema K, Reijngoud DJ, Bakker BM. The role of short-chain fatty acids in the interplay between diet, gut microbiota, and host energy metabolism. J Lipid Res. 2013;54.

59. Taranto MP, Medici M, Perdigon G, Ruiz Holgado AP, Font de Valdez G. Effect of Lactobacillus reuteri on the prevention of hypercholesterolemia in mice. J Dairy Sci. 2000;83:401-3.

\section{Figures}




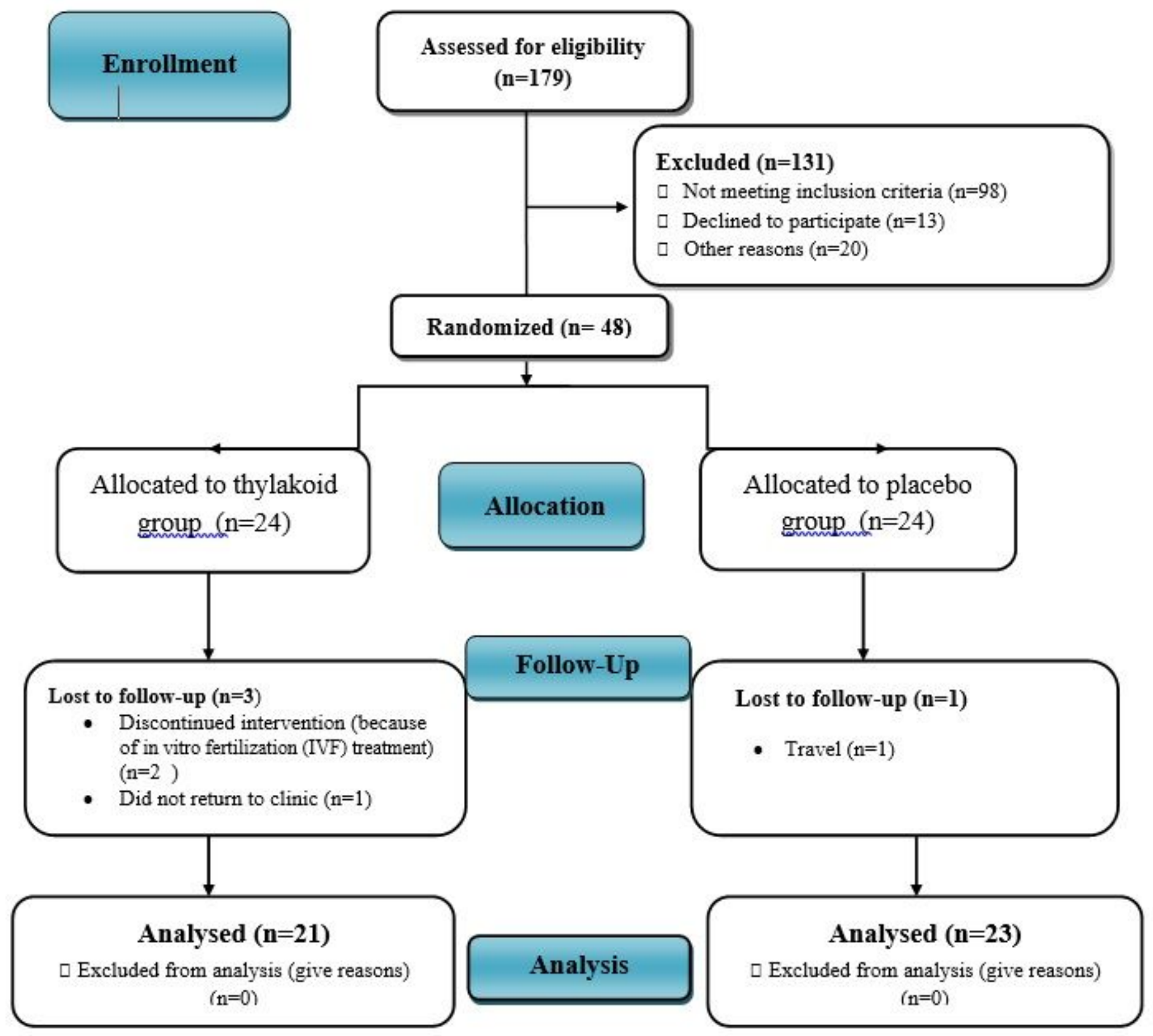

Figure 1

Follow of participants throughout the intervention

\section{Supplementary Files}

This is a list of supplementary files associated with this preprint. Click to download.

- CONSORT2010checklist.docx 